\title{
An Overview of the Recent Design and Construction of High Voltage Transmission Lines in Sri Lanka
}

\author{
G. R. V. Perera
}

\begin{abstract}
The construction of high voltage overhead transmission systems is a key element in electricity infrastructure development in any country. With about $45 \%$ of the homes in Sri Lanka yet to be electrified and the high demand growth in the areas already electrified, we will invariably have many electricity system development projects in our national electricity network in the near future. Construction of long lengths of high and medium voltage transmission lines and a large number of grid substations will be an integral part of this development process.
\end{abstract}

The development of local expertise in this field of design, manufacturing and construction of high voltage transmission lines and related electricity transmission and distribution systems and the turnkey construction of these projects, entirely by Sri Lankan Companies in recent years, have become a great advantage to the power sector of the nation. Maximizing similar local inputs into power sector development activities need to be encouraged by the authorities in order to reduce costs and keep electricity prices down.

\section{Introduction}

Sri Lankan engineers have been involved in the design and construction of major power projects including generation projects (both hydro and thermal), transmission and grid systems, and distribution networks over the past several decades. Originally, they worked as counterparts for foreign contractors (For example - $A B B$ (Germany/Nòrway), Betonmast As (Germany), Sri-U thone (Thailand), KEC (India), Hyundai (Korea), etc.) but, during the last few years, several such projects have been designed and constructed entirely by the Sri Lankan engineers (From LTL Projects (Pvt.) limited (Sri Lanka)) utilizing their own technical know-how, past experience, knowledge and expertise. They were able to successfully compete in a number of international tenders. Therefore, the capability of Sri Lankan engineers or their knowledge and expertise in handling major power projects are not in question any more.

We have two main hydropower-generating complexes (Laxapana and Mahaweli) and a number of thermal power plants. In addition, Sri Lanka has an interconnected grid system that operates at $220 \mathrm{kV}$ and $132 \mathrm{kV}$. Around $90 \%$ of the total $1700 \mathrm{~km}$ of the transmission network operates at $132 \mathrm{kV}$. The distribution network consists of over $15,000 \mathrm{~km}$ of $33 \mathrm{kV}$ and $2500 \mathrm{~km}$ of $11 \mathrm{kV}$ lines; the total length of the low voltage $(400 \mathrm{kV})$ distribution system exceeds $56,000 \mathrm{~km}$.
In this context, this paper confines its discussions to the design and constructional aspects of high voltage electricity transmission lines in Sri Lanka.

\section{The need for high voltage transmission lines.}

Virtually, all the hydropower-generating schemes are located far away from the main load centres of the country. They are located, for obvious reasons, in the central hills of the country, where water resources are naturally found. The power generated in these remote places is transmitted to load centres, which are invariably in and around the major cities.

Though, theoretically, the thermal power schemes can be located anywhere in the country, certain constraints such as the cost of fuel transport, the need to minimize transmission losses and environmental concerns, have restricted them too to pre-identified areas in the island and the power will have to be transmitted from such locations to the load centers. (For example - Two 100MW diesel power plants are recently under construction at Puttalam and Embilipitiya)

The interconnected grid system of the country is designed and developed to achieve optimum results with concerns for minimizing generation

Eng. G. R. V. Perera, BSc. Eng, C.Eng, MIE(SL), Presently working as a Project Engineer at Lanka Transformers Limited - 
costs, and reducing transmission and distribution losses.

. For minimizing the transmission losses of power during long distance power transmissions, appropriate voltage levels for transmission have to be selected. The level of voltage will vary according to the requirements, such as distance to be delivered, capacity of transmission line, cost of constructions, etc. However, $11 \mathrm{kV}, 33 \mathrm{kV}$, $132 \mathrm{kV}$ and $220 \mathrm{kV}$ voltage levels are used in the national electricity power transmission and distribution network in Sri Lanka.

\section{Design of transmission lines and it's profile or arrangements.}

\subsection{Preliminary design}

The prime purpose of having high voltage transmission lines is to transmit electricity energy from one place to another as economically and reliably as possible. Therefore, the concept behind the preliminary designing process also is transmitting the maximum energy between two points within reasonable cost and appropriate safety margins. The construction and maintenance of high voltage transmission lines is a high cost operation. It must be realized that at the end of the day all the above construction, maintenance and operational costs of transmission and distribution systems will be passed on to the customer. But, from the point of power transmission, the tower structures are nonproductive items. The general breakdown of the installed cost of a typical $132 \mathrm{kV}$ line in Sri Lanka is as follows,

\section{Productive cost}

Conductors

$30-40 \%$

Non-productive cost

Foundations

Towers

$30-45 \%$

Fittings, insulators, earth wire, etc.

$5-15 \%$

Land compensations, etc

$10-15 \%$

Therefore, the non-productive costs are much higher than the productive cost of the conductor and the towers and foundations constitute the major component of the non-productive cost. This underlines the importance of cost effective, optimum designs and construction work, without compromising on the safety and reliability of the transmission lines.
Also to minimize the construction and operational cost,

- Length of the Transmission line should be minimized.

- Cost of constructions should be minimized.

But, to maximize the energy delivering capacity,

- Cross sectional area (Size) of the conductor can be increased

- Higher voltage levels can be used.

During the preliminary design steps, designers try to reach a balance between the aforesaid different requirements, which are counter to each other and try to get the most practical solutions with optimal results. However, in the next detail designing stage all these solutions will be reconsidered and modified to accommodate safety requirements, environmental concerns, and also to conform and comply with the relevant public regulations and laws of the country.

\subsection{Profile design of the conductors.}

The main requirement of this process is to ensure that the live conductors are kept at an acceptably safe distance away from other structures, ground, etc. These minimum distances (clearances) to be maintained are different to each category of structures and they are clearly defined in the related regulations, and in the specifications too.

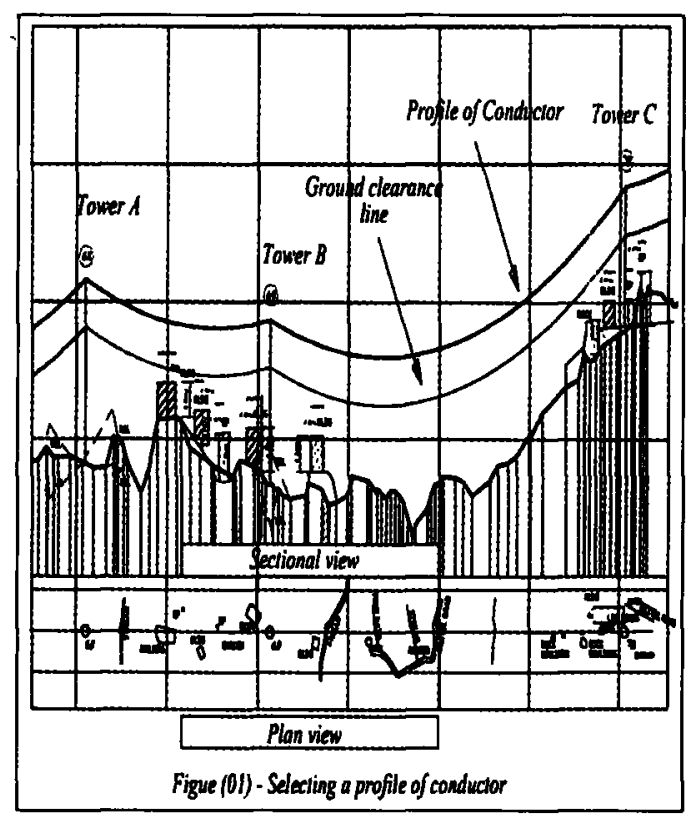


For example, some main clearances that need to be taken care of are as follows,

1. Minimum clearance between live conductors and ground, roads, roofs, buildings, etc.

2. Minimum clearance between two live conductors in the same line

3. Minimum clearance between live conductor and other structural parts in the transmission line itself ( such as cross arms, etc.)

4. Safety of the personnel engaged on maintenance work.

After preliminary assessments of the path of the proposed transmission line and level of voltage, capacity, arrangement of conductors, etc. the detailed survey works are started. From this survey details, decisions and conclusions are made with regard to the land surface profile and the heights of the existing structures (Buildings, LT line, Telephone line crossing, etc.) and other obstacles in the path of the proposed transmission line.

However, as a first step, designers will draw the calculated profile of the conductor for the maximum design sag condition. (For example, 75 degree / 350m wind span / No wind conditions). Thereafter, the towers will be located in the given surveyed land profile drawing, using the aforesaid calculated profile of conductors and keeping the lowermost conductor in accordance with the required ground clearances, etc. During this trial and error process of locating towers, the span between each tower, height and location of tower, etc., are determined.

Most of the present day transmission line designers are using special computer programs for this profile designing work. These computer programs give more flexibility to try various sensitivity checks on possible different arrangements and select the most economical arrangement of the towers for the proposed transmission line.

\section{Design of related structures such as steel lattice structures, pylons, etc.}

Traditionally, the transmission line towers were self-supporting (free standing) type of configuration. However, more recently, there is a growing need for higher power density and compact lines and due to the greater emphasis being laid on preservation of natural environment many innovative configurations like guyed towers and chainette towers are also available.
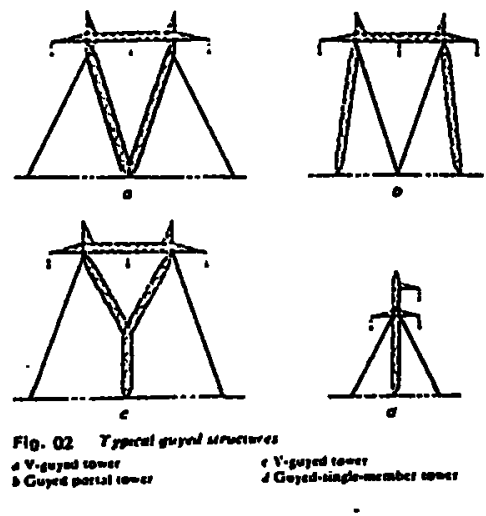

The design of transmission line structures involves careful optimization between reliability and economy, that is, getting the structure at the least cost with maximum reliability. The structural design of the towers is mainly governed by the combination of wind load and the other loads due to conductors, line deviations, broken wire conditions, cascading, erection and maintenance. The stress calculations in selfsupported steel lattice towers are usually based on conventional linear elastic analysis and this is generally found to be adequate, as the deflections are small in most cases.

Historically, the steel transmission line tower design has been based on truss modeling where the angle members only carry compression and/ or tension loads. These axial forces are then compared with calculated strengths based on standards such as ASCE-10 (Standard code of practice for design of lattice steel transmission structures published by The American Society of Civil Engineers). This design method has been proven fairly accurate when compared with fullscale testing.

However, the present design of members of the towers is based on the ultimate strength approach. The specific loads are multiplied by appropriate load / safety factors according to the specifications. The most important step in the design of towers is the calculation of the buckling stress, which depends on the effective lengths of various members. Even though guidelines are available in the above design codes, right understanding and experience are required to use the guidelines appropriately and to detail the 
structure accordingly so that it would behave in the way it is expected in the design.

The prime purpose of the conductor is for efficient power transmission and the earth wire is protecting the above line conductors from over voltages caused by lighting, by screening or shielding them. But, the arrangement or the architecture of self-supporting towers depends on the various requirements. Therefore, the arrangement of conductors and earth wire also can be changed accordingly.

During the structural designing, all the towers have to satisfy two sets of design conditions, "Normal condition", when all the conductors are loaded to tower as per basic design arrangements or service conditions. "Broken wire condition", when any one or more conductors are broken, then, broken wire condition involves working through a number of alternatives. Different safety margins will be employed for the above two different conditions. (Refer Table (01))

Table (01)

General safety factors for different loading conditions

\begin{tabular}{|c|l|r|}
\hline & \multicolumn{1}{|c|}{ Condition } & Safety factor \\
\hline 1 & Normal condition & 2.5 to 3.0 \\
2 & Broken wire condition & 1.25 to 1.5 \\
\hline
\end{tabular}

In Sri Lanka, above the $33 \mathrm{kV}$ voltage level, steel lattice structures ( steel pylons/ towers) only are used. When considering the single transmission line, it will consist of many different types and configurations of steel lattice structures. But there are two main types of steel lattice structures in any transmission lines, (Refer Figure (04)).

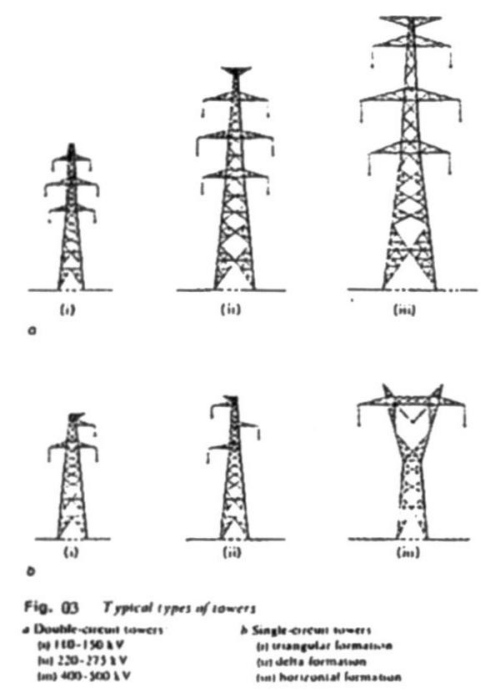

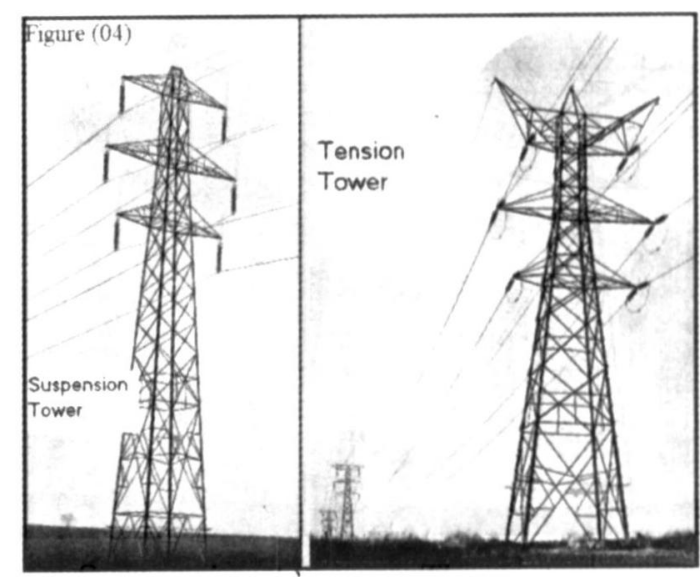

- Suspension towers - These structures are designed cnly to carry the weight of conductors in straight-line positions of transmission line. Therefore, all the conductor cables continuously run through these towers

- Tension towers - These towers are designed to terminate the conductors at each cross arm of the tower and therefore they can take the tension load of the cables too. The continuity of the cable for electricity power transmission will be provided by a separate jumper loop. Tension towers are generally used for turning points and for the section separating locations (in the straight sections) in the transmission lines.

The piece of line from one tension tower to the next is called a section. The length of the single section mainly depends on the land profile. All the other towers in between the two tension towers will be suspension towers. The most economical and lightweight structures in transmission lines are suspension towers. More than $60 \%$ of towers will be suspension towers in any transmission line.

Basically, there are different types of tension and suspension towers available during the designing of new power transmission lines. (Refer Table(02))

Towers of different heights can be obtained by using body extensions to the standard height towers. Also, using different leg extensions to each leg can compensate for different levels in the tower base (Refer Figure (07)). During the designing of towers, three different spans are usually employed. Basic span for computing the maximum sag between two towers: Wind span means half the wind load on the spans on either side of a tower that should be taken by 
Table (02)

Approximate steel weight of towers.

\begin{tabular}{|c|l|c|c|}
\hline Item & \multicolumn{1}{|c|}{$\begin{array}{c}\text { Type of tower } \\
\text { (for basic wind span=360m) }\end{array}$} & Notation & $\begin{array}{c}\text { Approximate steel weight } \\
\text { of single tower } \\
\text { (ZEBRA conductor) }\end{array}$ \\
\hline 1 & Suspension tower (or Line tower) & TDL & 4.0 ton \\
2 & $0-10$ degree tension towers. & TD1 & 6.0 ton \\
3 & $10-30$ degree tension towers & TD3 & 7.5 ton \\
4 & $30-60$ degree tension towers & TD6 & 12.0 ton \\
5 & Terminal towers & TDT & 15.0 ton \\
6 & Special towers such as river crossing & & $20-200$ ton \\
\hline
\end{tabular}

Table (03)

General wind \& weight spans for each type of tower

\begin{tabular}{|c|c|c|c|c|c|}
\hline \multirow{2}{*}{$\begin{array}{c}\text { Type of } \\
\text { tower }\end{array}$} & \multirow{2}{*}{$\begin{array}{c}\text { Basic wind span } \\
\text { at normal } \\
\text { condition } \\
\end{array}$} & $\begin{array}{c}|c| \\
\text { (in metres) }\end{array}$ & \multicolumn{2}{|c|}{ Normal condition } & \multicolumn{2}{|c|}{ Broken wire condition } \\
\cline { 3 - 6 } & & Maximum & Minimum & Maximum & Minimum \\
\cline { 3 - 6 } & 360 & 600 & - & 450 & - \\
TDL & 360 & 900 & -300 & 675 & -200 \\
TD1 & 360 & 900 & -300 & 675 & -200 \\
TD3 & 360 & 900 & -300 & 675 & -200 \\
TDT & 360 & 450 & - & 300 & - \\
\hline
\end{tabular}

the tower. Therefore the wind span is the main deciding factor of the span between any two towers in the transmission line. Weight span refers to the total weight of conductor on both sides that may occur to each of the towers. This will change according to the profile of the land. (Refer Figure (05))

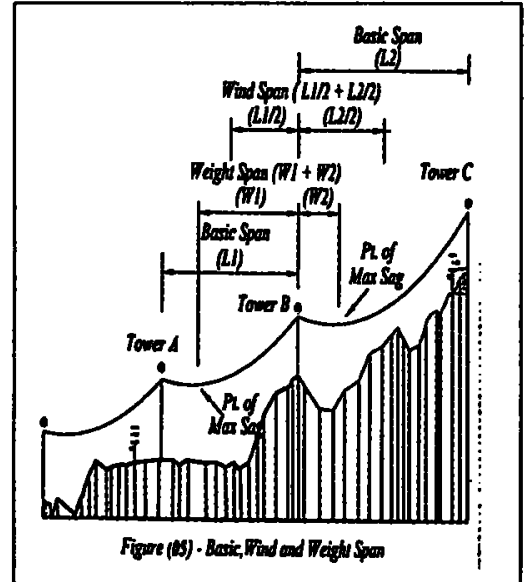

Apart from the above data (Table (03)) for basic weight span and angle of towers, we can utilize above towers as described in figure 06 too. This data is taken from the recently completed transmission line, which links one of the hydro power generating projects to the national electricity grid system in Sri Lanka.

When the ordinary suspension (TDL) towers are not strong enough to take the specific wind span in a transmission line, one of above tension towers ( Refer Figure-(06) ) can be used as a heavy suspension tower for that location after rechecking and confirming the design calculations. This type of situation frequently arises during the designing of transmission lines in steep mountainous terrains.

The transmission line profile designers use towers of different heights for inclusion in different locations according to the available land profile. Therefore the tower designers initially design each tower (TDL, TD3, etc.) to it's maximum height (Approx $40-50 \mathrm{~m}$ ) and 


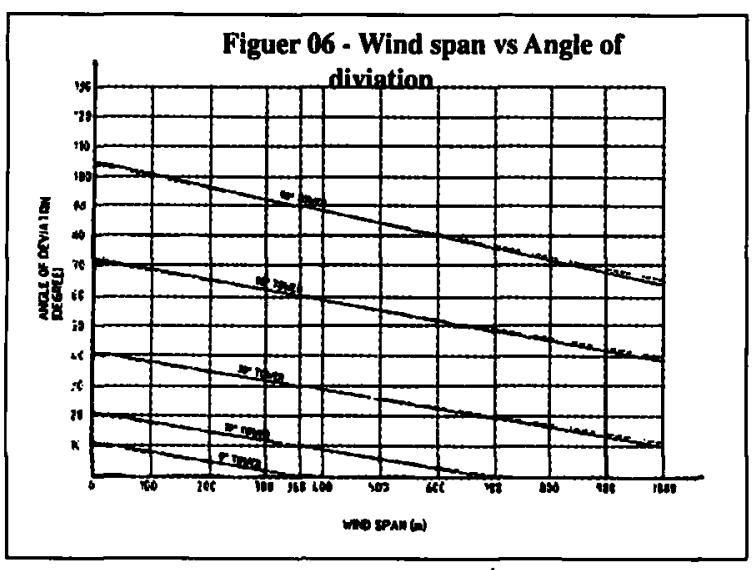

the architecture of those towers are arranged with flexibility to reduce their height steo by step (For Example - Reducing body extensions by $3.0 \mathrm{~m}$ steps) according to the site requirements. All towers with reduced heights/body extensions will be re-checked with the design calculations before use. One such architecture of the tower is shown in figure (07).(This is a locally designed steel lattice tower arrangement /architecture which has been used in the Kukule - Matugama $132 \mathrm{kV}$ transmission line)

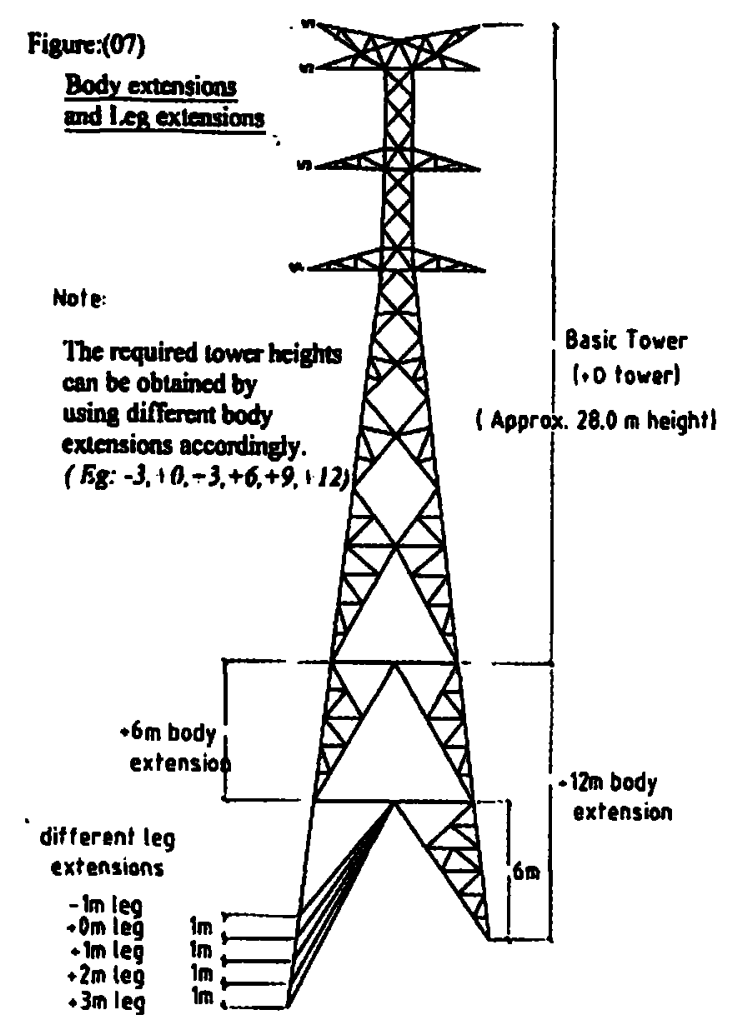

The structural analysis and design of structural members of the above lattice structures are also done with the help of computer programs in recent times. Therefore, the structural engineers can achieve the most accurate as well as sconomical results without difficulties.

\section{Manufacturing of steel lattice structures / pylons and cables}

\subsection{Manufacturing and testing of towers}

After the completion of the designing process, the fabrication drawings are prepared. The fabrication engineer must have a sound knowledge of the total design and construction aspects such as Structural designs, Profile designs, Materials and Fabrication, Transport and Tower erection procedures, Cable stringing and tensioning and the behavior of the towers during the actual site loading conditions, etc.

The fabrication of tower parts, in lattice towers, generally involves a large volume of repetitive work. Therefore, the use of numerical by controlled punching; drilling, and hard stamping machines are very common features in the modern steel fabricating industry. By the use of such high tech machines the quality as well as the speed of the manufacturing process are enhanced.

The fabrication tolerances, also, are of prime importance. Therefore, it is a normal practice to specify the tolerances required at the initial stages itself. These tolerances would cover such aspects as hole diameter, edge distance, end distances, hole center, length of bars, straightness, etc.

As a first step of fabrication, a prototype structure must be fabricated and erected in the fabrication factory premises under the design and fabrication engineers' direct supervision. During this process almost all the fabrication and erection difficulties and problems can be solved. Then the prototype tower should be tested and verified for the various loads and the combinations of loads that are considered during the designing process. These full-scale tests are essential not only to verify the design, but also to check the quality of materials, detailing, quality of fabrication, assembly and erection. The testing facility and procedures adopted should give confidence to the designer, fabricator and the user agency.

This type of testing can be done in testing bays available in India or Thailand. However the "art" in tower design, that is not readily available in textbooks, can be achieved only through experience. This experience is essential to avoid certain pitfalls, which, in practice, are found to cause premature failures. But this type of mistakes 
cannot be detected by calculations alone and can only be verified in full scale tests. However, the mass scale tower part manufacturing will be started only after all these tests are satisfactorily completed.

Almost all the structures for transmission lines, are invariably hot dip galvanized after fabrication to provide maximum protection against corrosion.

\section{Conductors and earth wires}

Economically, the conductor and earth wire cables represent between 20 to $40 \%$ of the total cost of line. Therefore, the selection of conductor and earth wire is of prime importance and the whole concept of electricity transmission and distribution also revolves around the conductors and earth wires.

Although copper was mainly used as material for overhead line conductors in the early days, the aluminum-based conductors are now widely used due to many reasons such as price, weight, availability, etc.

AAC - All aluminum conductors

ACSR - Aluminum conductor steel reinforced

AAAC - All aluminum alloy conductor

ACAR - Aluminum conductor alloy reinforced

The first two types are very common in Sri Lanka, but the other two types are rarely used due to the high cost of materials. (Refer Figure (08)).

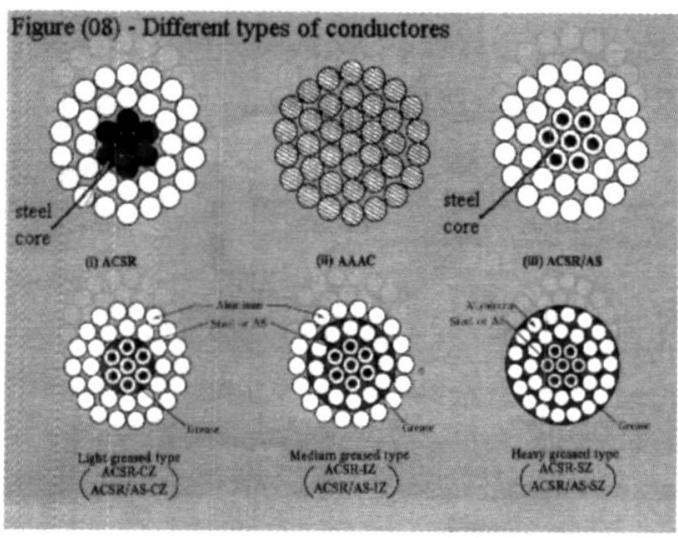

The basic selection parameters for conductors are their electromechanical parameters and the price. Earth wires differ from conductors only by their function, and from the point of view of lightning, the material is of no importance. Hence, in many lines, galvanized steel wires are used as earth wires.
The optical fiber incorporated conductors and earth wires are also used in high voltage transmission line systems recently. This is found to be a very efficient system for communications because optical fibers do not have electro magnetic induction and, as a result, there is little or no interference to signals/data resulting from electro magnetic induction.

\section{Construction of foundations and erection of steel structures.}

The foundat'on reactions are generally not high for the common lattice structures in this field. Therefore, the individual pad foundations for each leg are the common practice for the above structures and the construction is also a simple process. Only where extremely poor soil conditions are found at tower locations, pre cast concrete and pile driving will become necessary

Erection of these lattice structures needs some skilled personnel and supervisory staff. Although many different tower erection methods are practiced in the world, the selection of an erection method depends on various parameters such as the adaptability of selected method to each site conditions, time and the cost, etc. Heavy cranes or such other heavy equipment cannot be used in most of the transmission tower locations in Sri Lanka. Therefore, a piece by piece erecting process ( Refer Figure-(09)) is still the only cost effective method, available to Sri Lanka.

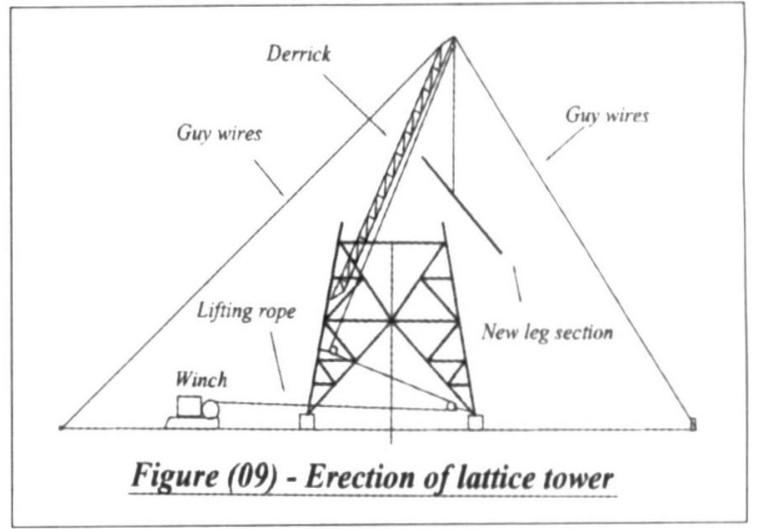

\section{Cable installations (cable stringing and clipping)}

After erection of the lattice structures, the cable stringing will be commenced. This is a special process, which needs highly skilled linesmen, supervisors, tools and machineries. These specialized tools and equipment are very cr.stly items and therefore only specialized foreign 
companies were involved in this type of projects until recent times.

Although this process slightly differs from site to site, the main idea behind the process is as follows:

1. The cable-stringing programme and schedule of cable drum usage is to be prepared. The conductor cables are the most costly item in these constructions. Therefore, cable wastages must be minimized during this process. Cable jointing, transporting of heavy winches and cable drums, temporary anchoring of towers, etc. are to be considered and the locations and method of stringing carefully selected. All these items must be included in the final schedule of drum utility.

2. Then the two (temporary) end towers are to be well anchored to the ground and their cross arms are also to be anchored to the body ( As extra reinforcement for the heavy dynamic loads that might occur during the cable stringing operations.). Also, the two cable stringing winches and cable drum jacks are to be well anchored to the ground and prepared for operations.

3. The special cable stringing pulleys with rubber sleeves (To avoid damage to the aluminum conductor when the cable runs through it) will be hung on the cross arms of the towers. The special anti-twisting and lightweight pilot wire will be kept (on the ground) along the line of towers and this pilot wire will be put trough the above rubber-sleeved pulleys on the cross arms of the towers.

4. Thereafter, the lightweight pilot wire should be wound to the two cable stringing winches at both ends and tensioned until the lightweight pilot wire comes well above the ground.

5. Then the heavy duty, anti-twisting, steel pilot wire will be attached to the above light weight pilot wire. The jointing device (swivel joint) of these two wires is specially designed for releasing any twisting force accumulated in either wire when running though the pulleys, capstan wheels of winches, etc. Excessive twisting must be avoided because it can very easily cause damages to the aluminum conductors as well as to the pilot wires.

6. The above lightweight pilot wire can be replaced by a heavy duty (steel) pilot wire by the process of pulling and releasing the two winches at the same speed. (Puller and Tensioner ). This operation is to be done without the wire touching the ground.(Refer Figure (10). The aluminum conductor cables are also strung following the same procedure using the heavy-d aty pilot wires.

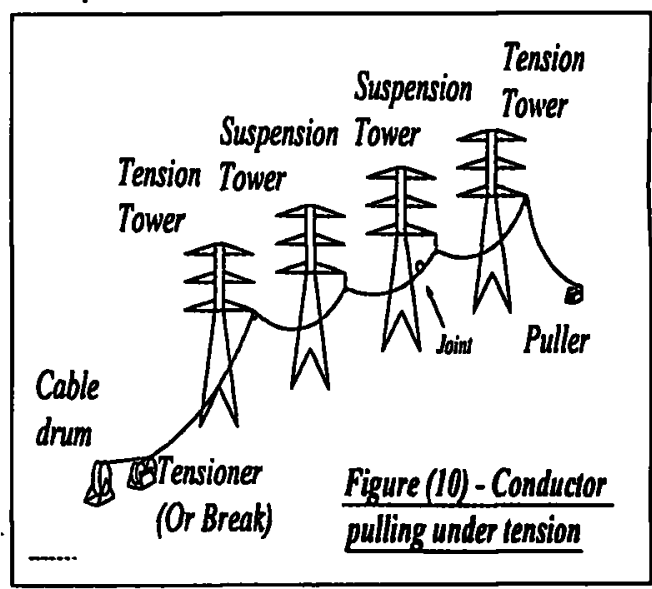

7. Thereafter, special come-along clamps that are designed for specific conductor sizes for avoiding damages due to slipping or over compression of aluminum conductor until it is permanently jointed will temporarily clamp the conductor cable. Well-trained skilled workmen do the cable jointing and termination by the process of coldwelding. Portable pressing tools (hydraulic or electric) are used to do this operation.

8. The final adjustment of the profile of the cable (Sagging) is done before final fitting of the cable ends in section towers. The long-term creepage is also to be considered during this final sagging operation. After sagging the conductors, the two ends of the conductors are fitted. Thereafter, the rubber sleeved pulleys on the suspension towers are replaced by suspension clamps and reinforcing rods. Finally the vibration dampers and jumper loofs will be fitted as may be necessary. 


\section{Testing prior to energizing the new transmission line}

The newly constructed transmission line has to be subjected to a series of tests and inspections before the initial energizing. These tests include visual inspection of cables, cable joints, insulators, getting measurements such as the arcing horn distances, resistance of jumper loops, line clearances and way leaves, checking the continuity of total transmission line, etc. These types of tests are of prime importance for the high voltage transmission lines, because any simple mistake or error can lead to serious accidents as well as costly damages during the initial energizing.

\section{Summary and Conclusions}

The construction of a high voltage overhead transmission system is a special field of construction. The construction of transmission networks in the developed countries has almost reached the saturation point. As a result, there is a decline in the availability of specialized designers, consultants and contractors in this field on an international scale and consequently the competitiveness has reduced. In the past, these high voltage lines and grid substations were designed and constructed for us by specialized foreign companies, and, because of the reasons stated above, the cost of transmission systems had been relatively high. .

The development of local expertise in this field of designing and construction of high voltage transmission lines and related electricity transmission and distribution systems in recent years has come as a great advantage to the power sector of the nation. Simultaneously, the development of the capahility of manufacturing most of the necessary high voltage conductors, galvanized steel lattice towers, steel structures, and other accessories in local factories have further erihanced the advantages.

The Ceylon Electricity Board has used locally manufactured galvanized steel structures, and high voltage aluminum (ACSR) conductors for several $132 \mathrm{kV}$. transmission lines that were constructed in recent years. (For example, $132 \mathrm{kV}$ transmission line from Kukule Ganga Hydropower project to Mathugama, Newly constructed Balangoda - Ratnapura $132 \mathrm{kV}$ Transmission line, etc.).
These major developments in the fields of engineering and manufacturing in Sri Lanka have resulted in huge savings to the country in addition to providing employment opportunities and other benefits to the nation. Encouragement of the development of indigenous skills and expertise, similarly, in other activities in the power sector will greatly help to contain the escalation of electricity tariff.

\section{References}

1. American Society of Civil Engineers, "Design of lattice steel transmission structures" ( ASCE 10 - 97 ), 1801, Alexander Bell Drive, Reston, Virginia, 20191-4400.

2. Dan E. Jakman, "Electrical transmission in the new age" American Society of Civil Engineers, 1801, Alexander Bell Drive, Reston, Virginia, 20191-4400.

3. American Society of Civil Engineers, "Guidelines for electrical transmission line structural loading" (0ASCE Manual No. 74), 1801, Alexander Bell Drive, Reston, Virginia, 20191-4400.

4. J. Varnakulasinghe, " $132 \mathrm{kV}$ transmission lines - design view points", technical paper presented to IESL, Sri Lanka on 10th September 1970.

5. J. Varnakulasinghe, "A $132 \mathrm{kV}$ transmission network" - the paper presented to IESL, Sri Lanka on 13th March 1974.

6. P.J. Ryle, "Steel tower economics" paper published in the IEE Journal Vol 93, Part II, No. 33 and No. 361946.

7. J.F. Adam, "Overhead lines - some aspects of design and construction" paper published in the IEE Journal Vol 131, Part I, No. 5, 1984.

8. Course document, "Advance course on steel transmission line and communication towers", Structural Engineering Research Centre, CSIR Campus, Chennai on December 2000.

9. John McCombe and F.R. Haigh, "Overhead line practice".

10. S.S. Murthy and A.R. Santhakumar, "Transmission line structures" McGraw-hill Book Co, New Delhi, India. 